\title{
Making bile duct injuries after laparoscopic cholecystectomy a 'near-never' event
}

\author{
J Lindemann, ${ }^{1,2}$ SR Thomson ${ }^{3}$ \\ ${ }^{1}$ Surgical Gastroenterology Unit, Department of Surgery, Faculty of Health Sciences, Groote Schuur Hospital, University of Cape Town, \\ South Africa \\ ${ }^{2}$ Department of Surgery, School of Medicine, Washington University, United States of America \\ ${ }^{3}$ Division of Gastroenterology, Department of Medicine, University of Cape Town Faculty of Health Sciences and Groote Schuur Hospital \\ Gastrointestinal Unit, South Africa
}

Corresponding author, email: Lindemannj@wustl.edu

In this issue of the SAJS two perspectives are opined highlighting the medicolegal and tangible and intangible consequences of bile duct injury (BDI). ${ }^{1,2}$ We learn from both that, for patient and surgeon alike, a BDI is a traumatic experience that often results in significant personal, financial and medicolegal burdens. No surgeon performs a laparoscopic cholecystectomy (LC) with the intention of injuring the bile duct, but the reality is that it does happen and even though the incidence may have returned to open cholecystectomy rates, many would agree the number remains too high. With all the ramifications of laparoscopic BDI the most important question to ask ourselves is how can we prevent it? This editorial focuses on injury prevention through implementation of an operative team checklist that mandates photo documentation of the critical view of safety (CVS), assists in inculcating a culture of safety and aids in assessing competency in surgical trainees.

"To Err is Human" highlighted deaths in US hospitals from avoidable medical errors and generated a global surgical interest in improving patient safety ${ }^{3}-$ a challenging task given significant potential for adverse events in a complex surgical care delivery system. Based on established efficacy in improving safety in the airline industry, checklists were introduced in surgery with a similar goal. The most notable example is the WHO Surgical Safety Checklist specifically designed to decrease errors, reduce adverse events and improve communication and teamwork in the operating theatre. Adopted worldwide, the WHO checklist resulted in a significant improvement in surgical morbidity and mortality. ${ }^{4}$ As a common general surgery operation with a potential for significant morbidity, LC makes an interesting and pertinent case study for checklist design and implementation. This is especially true for surgical training programs, as LC is considered an essential operation for young trainees to master.

The literature suggests that a lack of technical skills and experience alone do not explain the number of BDIs occurring annually. Anecdotally, referrals of BDI often come from experienced surgeons who never imagined they would be in their current position. Non-technical skills in surgery, including situational awareness, decision making, communication and team work, and leadership, have been identified as essential for successful surgical outcomes. ${ }^{5}$ Detailed retrospective video and operative note analysis of bile ducts injured at LC show that BDIs often occur due to a misperception of the biliary anatomy. ${ }^{6}$ The anatomical details of these so-called 'error traps' were more fully defined by Strasberg and provide evidence for the use of the CVS technique. ${ }^{7,8}$ The three components of the CVS are dissection of the lower third of the cystic plate, a hepatocystic triangle that is free of fibrous and fatty tissue, and two and only two structures entering the gallbladder. These are the key anatomical safeguards needed for an intraoperative checklist and must be achieved prior to clipping and dividing the cystic duct. ${ }^{8}$

The LC checklist also requires a pre-incision review of liver enzymes, radiology and consideration of whether the case is expected to be difficult due to, for example, a high BMI, male gender, previous upper abdominal surgery or a history of liver disease. All steps to attain the CVS must be confirmed with the assistant before proceeding, encouraging teamwork and communication and challenging the traditional hierarchical position of the surgeon. Preemptively, bailout techniques are listed for cases where the CVS cannot safely be achieved as are the steps for what to do if a bile duct injury is recognised intraoperatively. To accompany the checklist, a standardised operative note incorporating critical elements of the checklist, and anterior and posterior intraoperative photo or video of the CVS, are required to make best practice a habit.

Reference to the 'learning curve' for LCs was first made as a contributing factor to the increase in BDIs after the introduction of the technique in the late 1980s early 1990s. Today, the focus of the learning curve has shifted to surgical trainees. Contemporary studies suggest that a median of 70-90 LCs be completed before the trainee is competent to perform the operation alone, numbers that exceed criteria for graduation in many training programs. ${ }^{9,10}$ Simulation in the form of box trainers, virtual reality and porcine models have been investigated as a means to improve technical performance in theatre. ${ }^{11}$ A systematic review on the transfer of surgical skills gained in simulation to theatre for LC and endoscopic procedures showed encouraging results that translate into a reduced number of LCs needed to attain clinical competence. ${ }^{12}$

Whether through case volume alone or in combination with simulation, trainees should be guided to follow the best practices incorporated into the checklist and operative record. The challenges of assessing the technical and non- 
technical skills of surgical trainees is an often discussed topic, with its alphabet soup of acronyms for assessment tools, including direct observation of procedural skills (DOPS), the more recent video version, and the nontechnical skills for surgeons (NOTSS) assessment tool as the mainstays of both formative and summative assessment. ${ }^{13}$ Online platforms and phone applications hold promise, though they are still awaiting validation. ${ }^{14}$ The final arbiter, to ensure a minimum quality of performance for a routine general surgery operation and provide a means for trainee assessment, will be the blinded review of CVS images.

Ideally the checklist, standardised operative note and CVS image documentation will become the standard of care across the country. It is evident from another article in this issue on the management of acute cholecystitis that such a standardised approach to cholecystectomy documentation is not being followed in routine practice. ${ }^{15}$ It highlights the lack of complication details from such a retrospective analysis that detracts from the impact of their findings. Hence a national LC database should also be established as it has the potential to help us track progress, monitor quality and better understand the surgical management and outcomes after LC in the country as a whole. As outlined in the SAJS editorial of 2016 "Instilling a culture of safety for laparoscopic cholecystectomy", a laparoscopic checklist incorporating the key factors above and including photo documentation was adapted from the proposed checklist by Connor et al. and has been implemented at an academic centre in Cape Town, South Africa. ${ }^{16,17}$ The aim was to create a culture of safety for LCs and make BDIs a nearnever event by overcoming visual misperceptions, guiding intraoperative decision making, encouraging team work and communication, and improving trainee education.

\section{Conflict of interest}

The authors have no conflicts of interest to declare.

\section{Funding source}

None.

\section{Ethics approval}

Waived for editorial/current perspective manuscript.

\section{Plagiarism}

This work has not been previously presented or published and is not currently under review.

\section{REFERENCES}

1. Lindemann J, Krige J, Jonas E. The tangible consequences and intangible implications of laparoscopic cholecystectomyassociated bile duct injuries. S Afr J Surg. 2020;58(1):4-6.

2. Bass D. Laparoscopy and litigation: small access, small injuries, big trouble. S Afr J Surg. 2020;58(1):7-9.

3. Institute of Medicine. To Err Is Human: Building a Safer Health System. Nov 1999. Available from: http://www. nationalacademies.org/hmd/ /media/Files/Report $\% 20$ Files/1999/To-Err-is-Human/To\%20Err\%20is\%20Human $\% 201999 \% 20 \% 20$ report\%20brief.pdf [online]. Accessed 26 Dec 2019.
4. Haynes AB, Weiser TG, Berry WR, et al. A surgical safety checklist to reduce morbidity and mortality in a global population. N Eng J Med. 2009;360(5):491-9. Available from: https://doi.org/10.1056/NEJMsa0810119. PMID: 19144931.

5. Yule S, Parker SH, Wilkinson J, et al. Coaching Non-technical Skills Improves Surgical Residents' Performance in a Simulated Operating Room. J Surg Educ. 2015;72(6):1124-30. Available from: https://doi.org/ 10.1016/j.jsurg.2015.06.012. PMID: 26610355.

6. Way LW, Stewart L, Gantert W, et al. Causes and prevention of laparoscopic bile duct injuries: analysis of 252 cases from a human factors and cognitive psychology perspective. Ann Surg. 2003;237(4):460-9. Available from: https:// doi.org/10.1097/01.SLA.0000060680.92690.E9. PMID: 12677139.

7. Strasberg SM. Error traps and vasculo-biliary injury in laparoscopic and open cholecystectomy. J Hepatobiliary Pancreat Surg. 2008;15(3):284-92. Available from: https:// doi.org/10.1007/s00534-007-1267-9. PMID: 18535766.

8. Strasberg SM, Hertl M, Soper NJ. An analysis of the problem of biliary injury during laparoscopic cholecystectomy. J Am Coll Surg. 1995;180(1):101-25. PMID: 8000648.

9. Brown C, Abdelrahamn T, Patel N, Thomas C, Pollitt MJ, Lewis WG. Operative learning curve trajectory in a cohort of surgical trainees. Br J Surg. 2017;104(10):1405-11. Available from: https://doi.org/10.1002/bjs.10584. PMID: 28718887.

10. Abdelrahman T, Long J, Egan R, Lewis WG. Operative experience vs. competence: A curriculum concordance and learning curve analysis. J Surg Educ. 2016;73(4):694-8. Available from: https://doi.org/10.1016/j.jsurg.2016.01.011. PMID: 26966081.

11. Kowalewski KF, Garrow CR, Proctor T, et al. LapTrain: multi-modality training curriculum for laparoscopic cholecystectomy - results of a randomized controlled trial. Surg Endosc. 2018;32(9):3830-8. Available from: https://doi. org/10.1007/s00464-018-6110-7. PMID: 29435758.

12. Dawe SR, Windsor JA, Broeders JAJL, et al. A systematic review of surgical skills transfer after simulation-based training. Ann Surg. 2014;259(2):236-48. Available from: httsp://doi.org/10.1097/SLA.0000000000000245. PMID: 24100339.

13. Crossley J, Marriott J, Purdie H, Beard JD. Prospective observational study to evaluate NOTSS (Non-Technical Skills for Surgeons) for assessing trainees' nontechnical performance in the operating theatre. Br J Surg. 2011;98(7):1010-20. Available from: https://doi.org/10.1002/ bjs.7478. PMID: 21480195.

14. Sandher S, Gibber M. Assessing surgical residents; Challenges and future options. MedEdPublish. 2017;6(4):11-9. Available from: https://doi.org/10.15694/mep.2017.000177

15. Makatini GM, Mewa Kinoo S, Singh B. An audit of interval cholecystectomy for acute cholecystitis in a low resource healthcare system. S Afr J Surg. 2020;58(1):10-13.

16. Connor SJ, Perry W, Nathanson L, Hugh TB, Hugh TJ. Using a standardized method for laparoscopic cholecystectomy to create a concept operation-specific checklist. HPB (Oxford). 2014;16(5):422-9. Available from: https://doi.org/10.1111/ hpb.12161. PMID: 23961737.

17. Krige JE, Jonas E, Hofmeyr S. Instilling a culture of safety for laparoscopic cholecystectomy. S Afr J Surg. 2016;54(3):2-5 PMID: 28240459. 